\title{
The geotechnical evolution of deep level mechanised destress mining at South Deep
}

\author{
P.G. Andrews ${ }^{1}$, R. J. Butcher ${ }^{1}$, and J. Ekkerd ${ }^{2}$ \\ ${ }^{1}$ Gold Fields, Australia \\ ${ }^{2}$ Gold Fields, South Africa
}

\begin{abstract}
The South Deep mine is located approximately $45 \mathrm{~km}$ south-west of Johannesburg in the Far West Rand goldfield of the Witwatersrand Basin. It is a deep level mine that is actively mining between $2600 \mathrm{~m}$ and $3000 \mathrm{~m}$ below surface with expectations to mine to $3400 \mathrm{~m}$ depth.
\end{abstract}

South Deep is situated in the geologically unique and renowned Witwatersrand Basin, which is the world's premier gold region. The South Deep ore body gradually increases in thickness to the west, from approximately two metres at the sub-crop to approximately 120 metres in thickness. The geometry of the Upper Elsburg Reef package, which is the primary economic target, lends it to a fully mechanised mining method.

The main geotechnical challenges to successfully mine the South Deep orebody were to introduce a mechanised massive mining method at depth to destress and then extract the extensive orebody. The destressing method then had to allow a productive method for economic extraction of an essentially low-grade bulk volume orebody.

Several variations of different mining methods have been used to date but all rely on a destressing method to reduce the in situ stresses. Originally the destressing was done conventionally (traditional South African narrow reef gold mining methods).

Since Gold Fields acquired South Deep in 2007, the push for further mechanisation has seen four mining method changes, including: mechanised, low profile, apparent dip destress mining; the introduction of a low profile, horizontal destress method with backfill. The year 2011 saw the introduction of low profile, horizontal destress with $2 \mathrm{~m}$ wide crush pillars And in 2015, the mine moved to high profile (5.5m high) horizontal destress development with mechanised installation of ground support. Crush pillars were replaced with yield pillars.

\section{INTRODUCTION}

This paper outlines the geotechnical processes used to overcome issues as they were encountered, including ground support, seismicity, and rockmass conditions, and also highlights the key leanings of a deep level massive mine's evolution over time. For further details on seismicity at South Deep, refer to the companion paper: Seismic response to mining the massive ore-body at South Deep gold mine. 


\section{Location}

South Deep Gold Mine (South Deep) is situated approximately $45 \mathrm{~km}$ south-west of Johannesburg and $20 \mathrm{~km}$ south of Randfontein in the West Witwatersrand mining region. The entire mining area covers 3 563 hectares and extends for $9.5 \mathrm{~km}$ north-south and $4.5 \mathrm{~km}$ east-west at its widest points.

\section{Geology}

The geology at South Deep was defined by Watson et al (2014) as follows: The South Deep orebody lies within the Central Rand Group of the Witwatersrand Supergroup and is overlain by the Ventersdorp Lavas (See Figure 1). The Ventersdorp Contact Reef (VCR) and Upper Elsburg reefs are of the highest economic importance.

The Upper Elsburg reefs subcrop against the base of the VCR, which is a major stratigraphic unconformity. Towards the east, the orebody diverges and thickens up to about $120 \mathrm{~m}$ at the eastern extremity of the mine boundary, with an increasing percentage of non-profitable quartzite middlings in the thicker regions (See Figure 2). The targeted reef packages within the sequence are the EC and MB reefs. The dip and strike of the orebody varies across the mine, but it generally dips to the south at between $10^{\circ}$ and $14^{\circ}$. This dip-angle is too steep for normal mechanised equipment due to excessive loading on braking components.

The orebody is currently being mined at depths of between $2600 \mathrm{~m}$ and $3000 \mathrm{~m}$, and future mining is planned at $3400 \mathrm{~m}$ below surface, respectively. The virgin vertical stress is high and will become higher as the depth of the overburden increases.

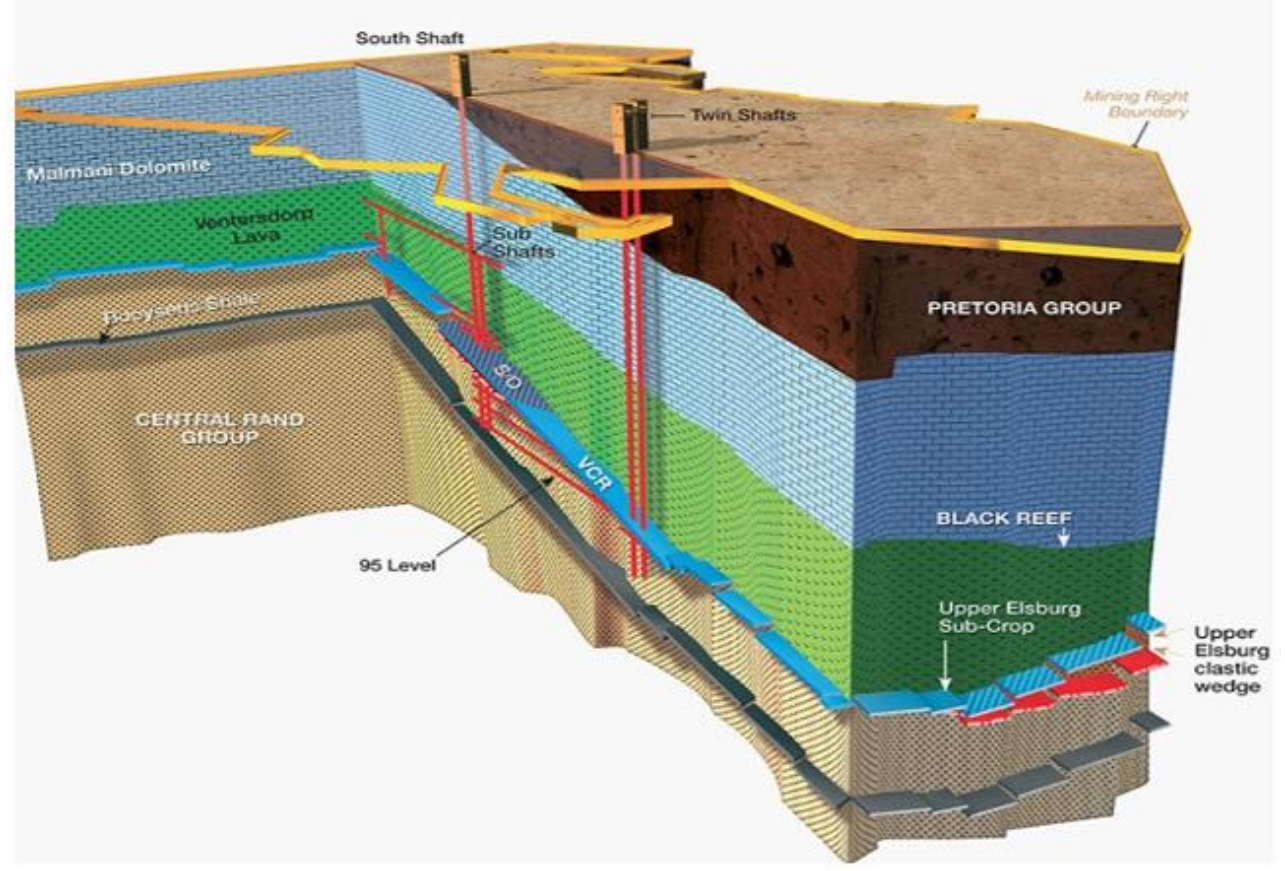

Figure 1. Simplified 3D section showing the stratigraphy around the strategic reefs 


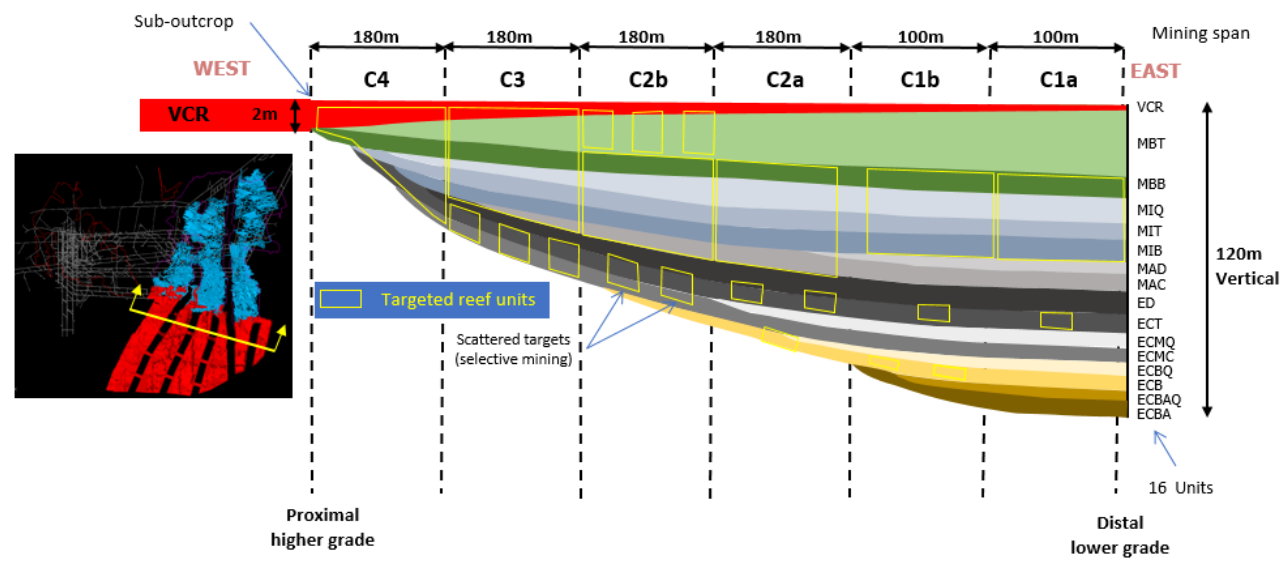

Figure 2. Generalised east-west section showing the stratigraphy of the orebody, targeted reef units and corridor geometry.

\section{Mining}

Over the years, several different mining methods have been used at South Deep to maximize extraction of the large orebody, whilst trying to ensure that these are the safest and most cost-effective mining methods available. Since Gold Fields acquired the mine in 2007, several methods have been trialled and abandoned during the past 11 years. This optimisation work has been an ongoing process, as the level of knowledge and confidence in each of the methods increased.

The underlying principle of all methods is that a narrow tabular cut is mined first. This cut destresses the orebody directly above and below this cut, ensuring the safest and most cost-effective extraction of the orebody.

The destressing philosophy will be discussed first followed by the description of the various the mining methods used by Gold Fields for the extraction of the destress mining layouts. Extraction sequences for the massive mining will then be discussed. In all methods, backfill plays an integral role and the backfill practices for each method are discussed.

\section{GEOTECHNICAL ENVIRONMENT}

\section{Rockmass conditions}

Most of the conglomerate units within the Upper Elsburgs are extremely strong, brittle rocks. SRK (2006) identified three rock strength classes within the Upper Elsburg reef package:

- Argillaceous and gritty quartzites are the lower strength parts of the package, although they are still generally strong, with $\sigma_{c}$ ranging from 80 to $150 \mathrm{MPa}$.

- Medium strength, sub argillaceous to siliceous quartzites with $\sigma_{c}$ ranging from 150 to $\sim 200$ MPa.

- High strength siliceous conglomerates and quartzites with $\sigma_{c}>200 \mathrm{MPa}$.

The RMR within the reef package is variable but generally high with many RMR values over 80 . Based on geotechnical logging and mapping, the geological strength index (GSI) range from 55 to 75 .

\section{Stress field}

The virgin stress tensor used in the modelling was determined from stress measurements using CSIR cells, carried out at a depth of $2650 \mathrm{~m}$ below surface. SRK (2009) provides the in situ stress field as summarised in Table I. 
Table I. In situ stress field used for numerical modelling purposes from SRK (2009)

\begin{tabular}{|c|c|c|c|c|}
\hline $\begin{array}{c}\text { Principal } \\
\text { stress } \\
\text { component }\end{array}$ & $\begin{array}{c}\text { Magnitude } \\
\text { gradient } \\
(\mathrm{MPa} / \mathrm{km})\end{array}$ & Dip & $\begin{array}{c}\text { Dip } \\
\text { azimuth }\end{array}$ & $\sigma_{i} / \sigma_{z z}$ \\
\hline$\sigma_{1}$ & 27.0 & 90 & 000 & 1 \\
\hline$\sigma_{2}$ & 24.0 & 00 & $000=180$ & 0.89 \\
\hline$\sigma_{3}$ & 16.0 & 00 & $090=270$ & 0.59 \\
\hline
\end{tabular}

\section{Destress philosophy}

In high stress environments, the rocks store of the Upper Elsburg package strain energy that can be released violently in the form of rockbursts. The solution was to mine a narrow tabular cut, which would then destress the orebody above and below to allow normal massive mining techniques to be conducted, James et al (1998). Initially, conventional destress cut mining was used at South Deep as this method is used extensively at depth in South Africa.

Early elastic numerical modelling work indicated that an optimum conventional destressing cut could be achieved with backfill with a stoping width of $1.5 \mathrm{~m}$ to $2.0 \mathrm{~m}$. To ensure that average energy release rates (ERR) were maintained below the mining-industry accepted average energy release criterion of $30 \mathrm{MJ} / \mathrm{m}^{2}$, Jager and Ryder (1999), the panels in the destress cut were limited to $250 \mathrm{~m}$, separated by 60 $\mathrm{m}$ wide stability pillars. Later modelling showed that the vertical stress could be reduced to $\sim 30 \mathrm{MPa}$ to $40 \mathrm{MPa}$ up to $60 \mathrm{~m}$ above and below the destress cut. (See Figure 3). The destress envelope that was created had stresses one would expect at a depth of $1200 \mathrm{~m}$.

Backfill therefore, is the most crucial support element. This destress cuts had to be backfilled to limit bedding separation in the hangingwall, provide areal support and energy absorption capacity.

While mining the destress cuts conventionally worked well, the rate of destress advance was slow and did not open up enough of the mining areas to achieve the required production rates for long hole stoping.

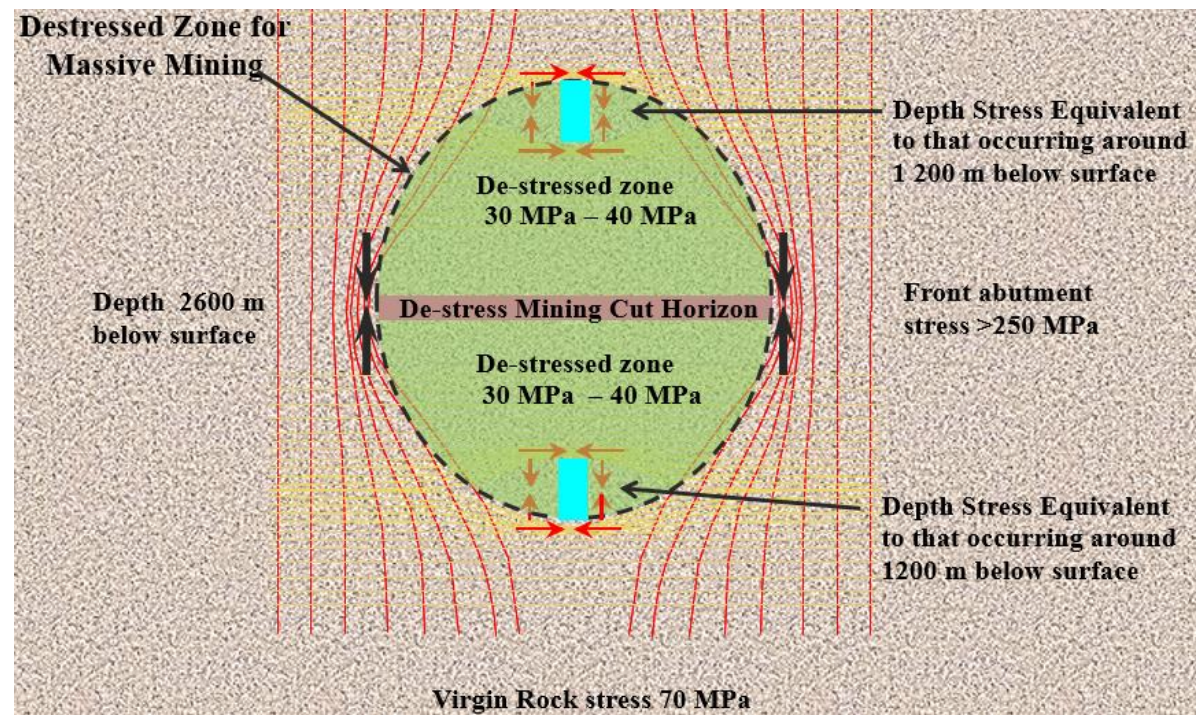

Figure 3. Sectional view of the destress concept. The vertical stress trajectories are shown in red 


\section{MECHANISED DESTRESS MINING HISTORY}

\section{Mechanised destress mining (Apparent dip)}

The mechanised apparent dip destress method started in 2008. This was the first mechanized destress method implemented and it involved mining a combination of apparent dip drives to excavate the target destress cut horizon in the plane of the reef (See Figure 4). Development was $2 \mathrm{~m}$ high and $4 \mathrm{~m}$ wide. The concept was to mimic conventional destressing using mechanised equipment.

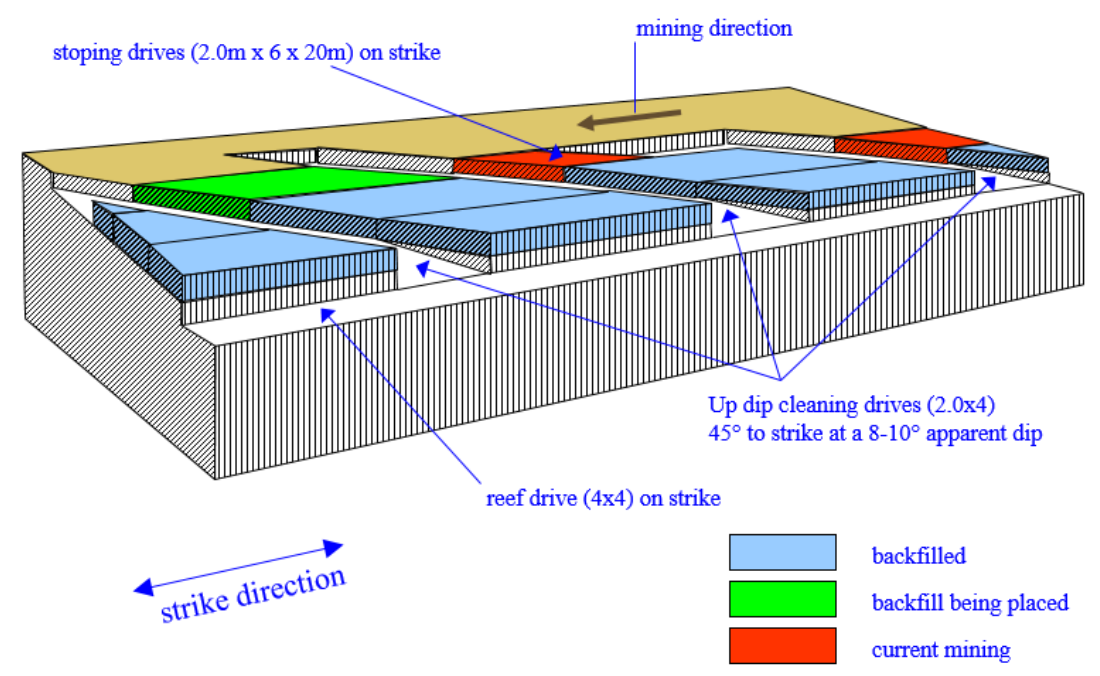

Figure 4 - Oblique view of the mechanised apparent dip destress mining method.

\section{Ground Support Systems}

Hangingwall support initially comprised $46 \mathrm{~mm}$ diameter friction bolts and $5.6 \mathrm{~mm}$ gauge weld-mesh. When mining using this method, friction bolts are being phased out and replaced by more robust flexianchors as an interim measure. It was planned to eventually replace the anchors with yielding reinforcement to provide the necessary energy absorption requirements.

Once the stoping drives were completed, they were backfilled with cemented classified tailings (CCT). There was no need to construct a backfill paddock as the bulkheads were formed using POWERITETM bags, which are filled with CCT. Backfill is contained by the two bulkheads, previously placed backfill and the rock face.

\section{Seismicity}

The energy release rates associated with this layout are equivalent to that of conventional mining with the same regional pillar configuration. In principle, the destressing effect was presumed to be identical to that achieved with conventional destressing. Larger events clustered around geological structures and stabilisation pillars whilst smaller events $\left(\mathrm{M}_{\mathrm{L}} 0.0\right.$ to $\left.\mathrm{M}_{\mathrm{L}} 2.0\right)$ were concentrated around the destress mining front.

\section{Issues and method change}

The apparent dip mechanised mining of the destress slot was discontinued in late 2008. Issues with the method included:

- Difficulty in maintaining development on the correct ore horizon, especially when encountering faults.

- Delays in backfill and difficulties in getting tight fill against the hangingwall with bags.

- Ground support still installed conventionally, as mechanised bolting was not viable due to the narrow mining heights. Very little synergy with massive mining. No shared development. 


\section{Low profile mechanised destress mining (Horizontal destress)}

The horizontal destress method with no pillars was used from 2009 to 2012. This method involved mining layered horizontal destress cuts. These horizontal cuts overlap and destress the target mining horizons (See Figure 5). Access to the destress cut was obtained through a spiral decline, which is located beneath a previously mined area and is always destressed. Access drives were developed horizontally from the spiral decline to each horizontal destress horizon. The mining corridor width of $240 \mathrm{~m}$ between stability pillars was maintained. There was a $17 \mathrm{~m}$ vertical spacing between destress cuts.

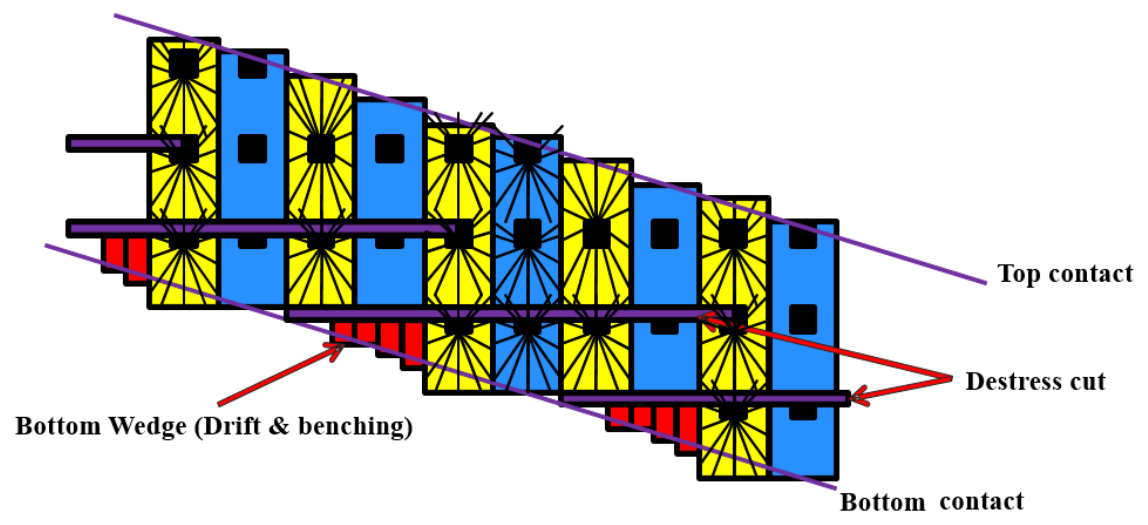

Figure 5 - Cross section of the horizontal destress layout

Each horizontal cut was mined as a series of perpendicular drives, which used set leads and lags to mitigate potential rockburst and stress damage. All development was planned at $5.0 \mathrm{~m}$ wide and $2.2 \mathrm{~m}$ high (See Figure 6). Main access drives (MADs) are developed in the dip direction, Watson et al (2014). Stoping drives (SDs) are mined adjacent to the MADs on a modified drift-and-fill sequence. Strike access drives (SADs) are created on strike every $10 \mathrm{~m}$ by placing backfill in the SDs. This ensures that crossfracturing in the SAD hangingwall is avoided. The plan was to integrate this destress cut and subsequent longhole stoping, by utilizing the original destress cut drives. These drives would be filled after the destress cut was completed. Re-developing through the fill was required with backs stripping or footwall slipping being undertaken to create the final dimensions of the longhole stoping access drives designed to be at least $5.0 \mathrm{~m}$ high $\times 4.5 \mathrm{~m}$ wide. 


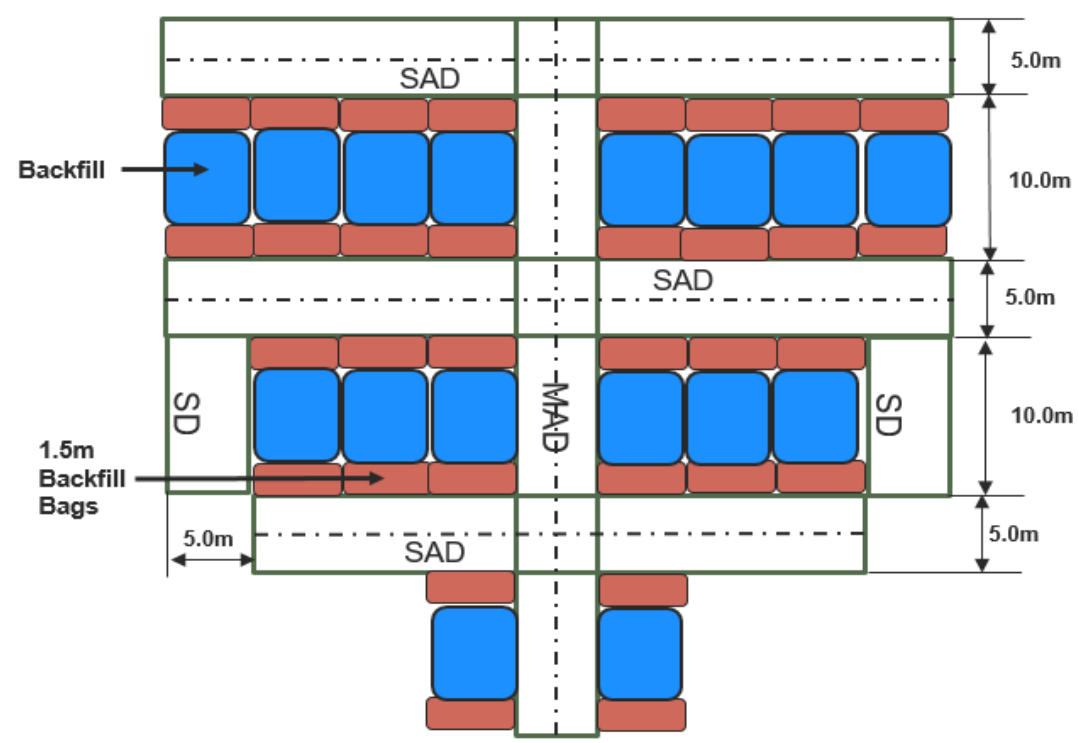

Figure 6. Plan view of the horizontal destress layout

This mechanised horizontal destress method had several perceived advantages over the apparent dip destress method, Joughin et al (2011), including:

- Development layout synergies with the subsequent massive mining.

- The ramp infrastructure can be utilized for massive mining.

- The destress cut access and strike drives could be utilized for subsequent longhole stoping.

- Higher grade ore from destressing development.

- Adjustments to the layout are not required to accommodate geological structures as would be the case with an apparent dip layout.

- Having the destress within the trackless target horizon maximizes the destress envelope.

- Multiple longhole stopes can be stacked on top of each other to form one large stope.

\section{Ground support systems}

Ground support continued to use the $46 \mathrm{~mm}$ diameter friction bolts and $5.6 \mathrm{~mm}$ gauge weld-mesh in the development in existing destress shadows. Destress development into higher stress abutments used the Flexibolt, a yielding anchor from M\&J mining. Dynamic yield is achieved by dragging $300 \mathrm{~mm}$ of cable, located at the back of the anchor, through a small orifice at the position of the anchor. However, yielding bolts were still installed and tensioned conventionally.

\section{Ground performance}

Overall, rockmass conditions post extraction were considered fair. If backfill was placed on time and installed tight against the hangingwall, then hangingwall conditions were good. Often, backfill was installed late or not installed tight against the hangingwall. This caused hangingwall conditions to deteriorate with opening along bedding planes and large-scale convergence observed up to $\sim 500 \mathrm{~mm}$.

\section{Production}

The horizontal destress method was used for 3 years from 2009 to 2012. Production over this time was $\sim 1.4 \mathrm{Mt}$ in $2009, \sim 1.75 \mathrm{Mt}$ in 2010 , and $\sim 1.98 \mathrm{Mt}$ in 2011 . During these years $\sim 56 \%$ of total tonnes came from development (destress, normal and new mine development) and $44 \%$ came from some form of stoping (longhole, or drifting and benching). The large amount of development was to set up stoping areas in the future.

\section{Seismicity}

Whilst mining in this method, seismic activity averaged around 40 events $>\mathrm{M}_{\mathrm{L}} 0.0$ per month. Larger events clustered around pillars whilst smaller events $\left(\mathrm{M}_{\mathrm{L}} 1.0\right.$ to $\left.\mathrm{M}_{\mathrm{L}} 2.0\right)$ were concentrated around the 
destress mining front. The was a moderate correlation between the number of events per month and production. The monthly seismic energy released was between $5 \mathrm{MJ}$ and $180 \mathrm{MJ}$ with the average being $\sim 45 \mathrm{MJ} /$ month.

\section{Issues and method change}

The mechanised horizontal destress method was used for two years between 2009 and 2011. During this time, several issues were noted with the method including:

- Difficulty in maintaining $90^{\circ}$ turnouts on the destress horizon, turn-outs became large and required more backfill bags to reduce spans.

- Difficulties mining on-line and on-grade.

- Delays in backfill which caused delays in development and future stoping.

- Difficulties when tightfilling to the backs with backfill bags.

- Convergence in the centre of the destress cuts $\sim 500 \mathrm{~mm}$. this was exasperated by backfill delays.

- Bags only provide support when closure occurs.

Due to issues with backfill delays and convergence the horizontal destress method morphed in a horizontal destress method with crush pillars (LPS). Trials of the method began in 2012 with the method being fully adopted in 2013.

\section{Low profile mechanised destress mining with crush pillars (LPS)}

This method involved the addition of crush pillars in the horizontal destress cuts (LPS). The crush pillar concept can be defined as pillars intended to crush while they are still part of the face, but which have sufficient residual strength to provide the required support resistances to the immediate hangingwall, both at the face and in the back areas. These pillars can yield over a large deformation range at their residual strength level, Ozbay et al (1995).

The LPS method was utilised for 3 years from 2012 to 2014. Access to the destress cut was still obtained via a spiral decline. Access drives still developed horizontally from the spiral decline to each horizontal destress horizon. The mining corridor width of $240 \mathrm{~m}$ between stability pillars and the $17 \mathrm{~m}$ vertical spacing between destress cuts were maintained.

There were many expected advantages from the transition to LPS were documented, Watson et al (2014). These included:

- Less backfill required.

- More heading availability.

- The crush pillars are an active support system and would inhibit hangingwall unravelling, which is often observed where the reef is replaced by backfill.

The destress development still used the $5.0 \mathrm{~m}$ wide and $2.2 \mathrm{~m}$ high design. Main access drives (MADs) were first developed in the dip direction (See Figure 7). Stope drives (SDs), were then mined adjacent to the MADs in a staggered configuration to maintain acceptable lead-lag distances. This distance was originally designed to create a $1.5 \mathrm{~m}$-wide crush pillar, but was expanded to a $2.0 \mathrm{~m}$-wide crush pillar. Stope access drives (SADs) were developed at $15 \mathrm{~m}$ spacing's by cutting $5 \mathrm{~m}$ holing's through the crush pillars at the appropriate locations. PoweRite ${ }^{\mathrm{TM}}$ backfill bags were installed along the edge of the crush pillars to provide confinement to the pillars and to reduce pillar disintegration at large closures. 


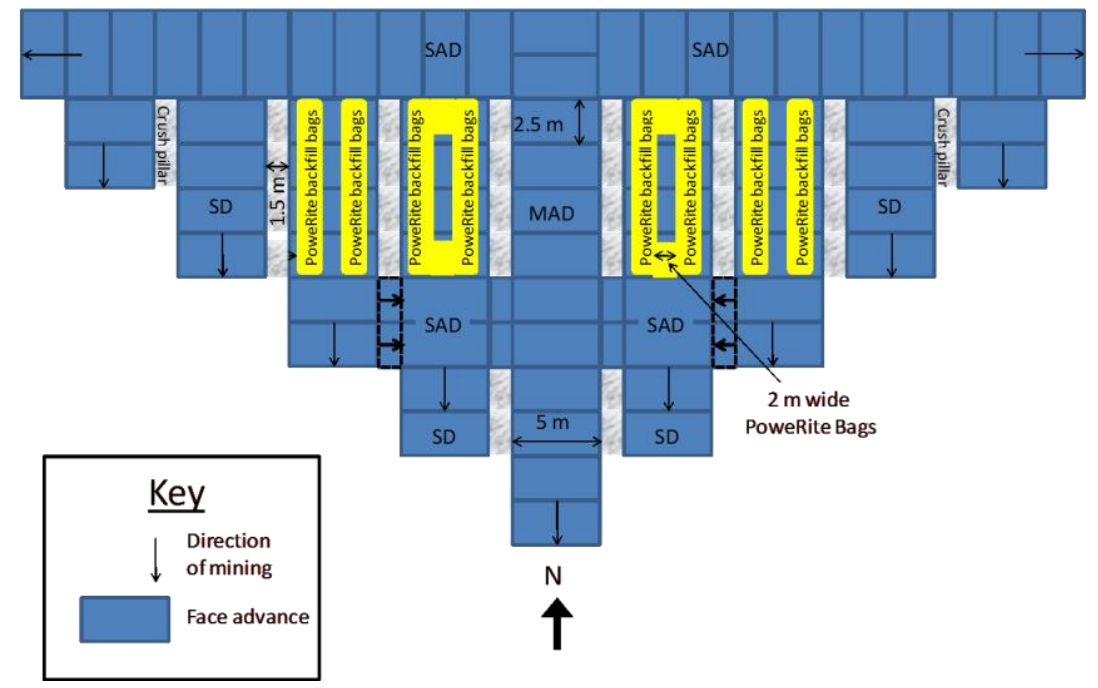

Figure 7. Plan view of the horizontal destress with crush pillar layout

\section{Ground Support Systems}

Ground support in destressed rockmass used the $46 \mathrm{~mm}$ diameter friction bolts and $5.6 \mathrm{~mm}$ gauge weldmesh in the development. The sidewalls of the MAD are also supported with friction bolts and weldmesh. The hangingwall of the destress development into higher stress abutments was supported with $5.6 \mathrm{~mm}$ diameter weld-mesh and yielding tendons. Yielding bolts continued to be installed and tensioned conventionally. Many of the Flexibolt could not be installed properly as proper tensioning of the bolts could not be undertaken. This allowed bolts to loosen and slip, causing further dilation of the hangingwall.

\section{Ground performance}

Rockmass conditions within the destress cut post extraction were considered poor. Crush pillars deteriorated quicker than expected and provided very little post-peak load capacity (See figure 8a). Late placement of backfill saw hangingwall deterioration with large openings in bedding planes occurring (See figure $8 \mathrm{~b}$ ). Convergence was high with closure $>500 \mathrm{~mm}$ seen in many of the destress cuts.

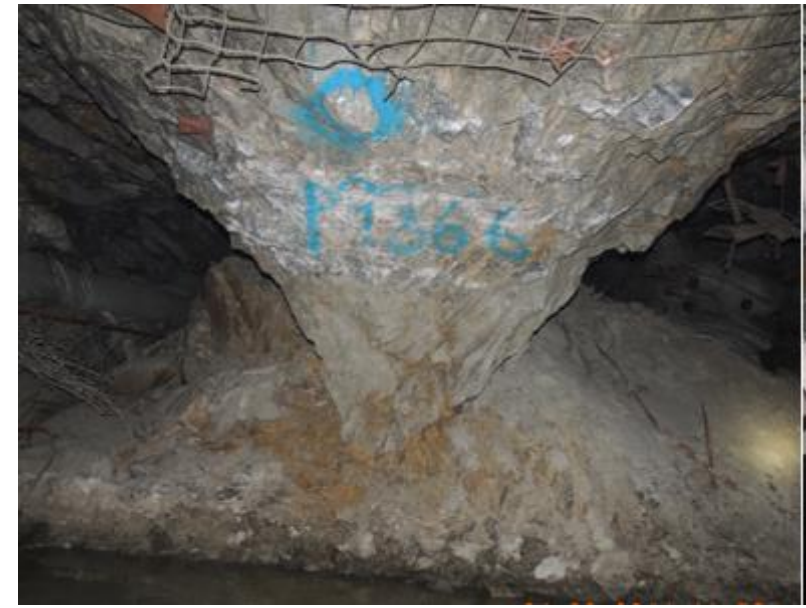

Figure 8a. Deteriorated crush pillar in LPS

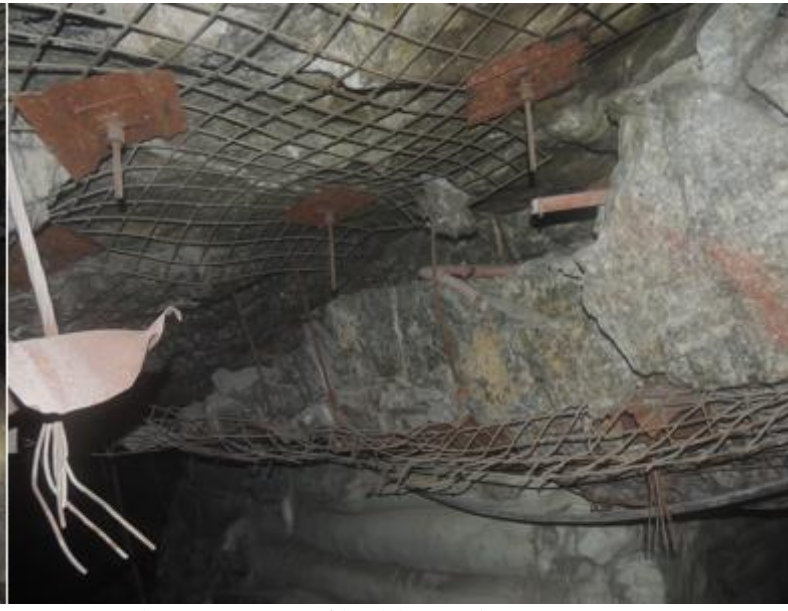

Figure 8b. Opening of bedding planes in LPS

\section{Production}

This method was utilised for 3 years from 2012 to 2014. The first 2 years' production were very good with over 2.05Mt extracted in 2012, and 2.24Mt in 2013, however, due to poor ground conditions and the required remediation, there was a significant decrease in tonnes in 2014 with only 1.09Mt extracted. 
During these years, some $60 \%$ of total tonnes came from development and some $40 \%$ from stoping.

As can be seen from the production results, the reduction in the need for backfill saw a significant increase in extraction rates for 2 years. Backfill requirements fell further behind as significantly more bags to fill at more locations was required by the new method. This lack of backfill reduced pillar confinement which allowed pillars to fret away causing large convergence within the destress cuts. The large levels of convergence prevented productive mining due to the extra rehabilitation and backfill requirements.

\section{Seismicity}

During 2012 and 2013, seismic activity averaged around 60 events $>M_{L} 0.0$ per month. Whilst mining with the LPS method, the number of events magnitude $\mathrm{M}_{\mathrm{L}}>2.0$ increased from a historical average of $1 /$ month to 1.8 /month. The was a moderate correlation between the number of events per month and production.

From January 2012 to March 2013, the monthly seismic energy released was between 5 MJ and 90 MJ with the average being some $30 \mathrm{MJ} /$ month. However, April 2013 to January 2014 the monthly seismic energy released increased to between $40 \mathrm{MJ}$ and $200 \mathrm{MJ}$ with the average being some $100 \mathrm{MJ} / \mathrm{month}$. The increase in the energy released, the number and magnitude of events whilst using the LPS method is attributed to the high levels of convergence caused by the crush pillars over-crushing and losing all load bearing capacity (See Figure 9).

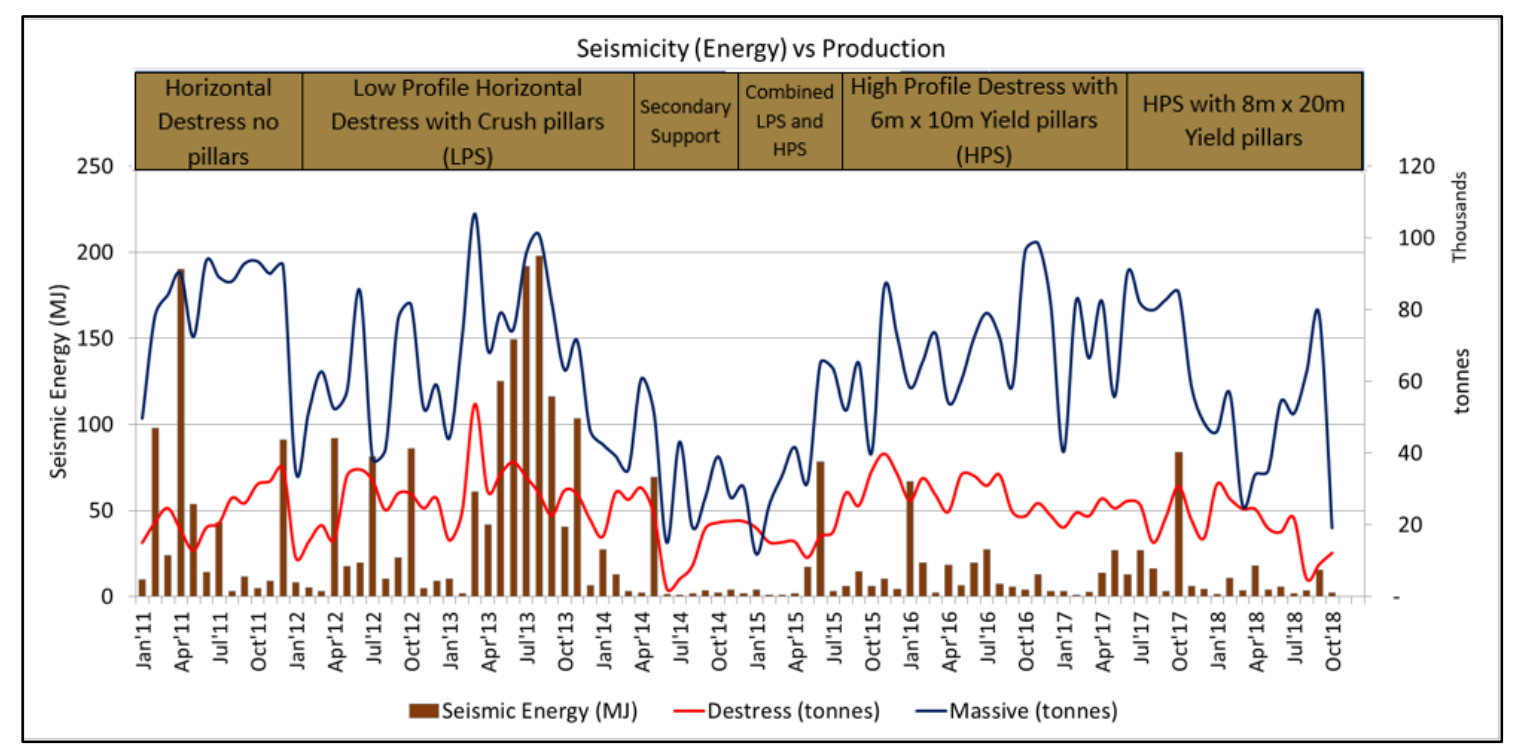

Figure 9. Seismic energy versus production for the various mining methods

\section{Issues and method change}

The mechanised horizontal destress method was used for two years between 2012 and 2014. During this time, several issues with the method were noted, including:

- Convergence in the centre of the destress cuts $\sim 500 \mathrm{~mm}$ as crush pillars deteriorated.

This created very poor working conditions.

- The convergence was accelerated by backfill delays.

- Difficulty in maintaining $90^{\circ}$ turnouts on the destress horizon, as turnouts became large and required more backfill bags to reduce spans.

- Difficulties mining on-line and on-grade.

- Delays in backfill which caused delays in development and future stoping.

- Difficulties when tightfilling to the backs with backfill bags. 
After the poor performance in early 2014, Gold Fields management instated a geotechnical review board (GRB) to review and comment on the LPS mining method. The results of the GRB review of the LPS method indicated that the LPS method was flawed owing to the issues noted above. The report outlined many short-term remediation strategies, including flood-filling certain areas to control convergence and a regime to catch up on a backlog of secondary support. These recommendations were carried out and impacted on the 2014 production figures.

The main medium to long term recommendations were to continue using the destress method but moving to a larger development profile to ensure mechanised support installation. Pillars were to be larger but still designed to yield to prevent pillar bursts. Also recommended was an investigation to look at a reduction in the corridor spans to control convergence.

\section{High profile mechanised destress mining with yield pillars (HPS)}

During late 2014 and early 2015, much work was done on recommendations provided by the GRB. Many areas were flood-filled based on rockmass conditions, and production was further impacted due to the work on the secondary support backlog.

The outcome of this work was the creation of the high profile mechanised destress mining method with yield pillars (HPS). Further work was done on detailing the new method and then numerical modeling of these new designs.

Yield pillars are pillars which are intended to have a SF $>1$ or even SF equal to 1 when first formed, but then yield in a stable manner at stress levels near to peak strength, Ozbay et al (1995). The pillars are sized, often using empirical and observational approaches so that they do not store excessive strain energy and burst, but remain intact enough to maintain a residual strength. In practice, yield pillars are intact when formed and are then weakened as the load on them increases beyond their load- bearing capacity, causing them to yield.

The new method involved the following changes:

- Increase the destress development profile to $5.0 \mathrm{~m}$ high $\times 4.5 \mathrm{~m}$ wide to allow for mechanised support installation.

- Change crush pillars to yielding pillars. The original size of the pillars was to be $6 \mathrm{~m}$ wide by $10 \mathrm{~m}$ long;

- This was changed to $8 \mathrm{~m}$ wide $\times 20 \mathrm{~m}$ long yield pillars in 2017 (See Figure 10).

- Mechanised ground support changed to include dynamic support as primary support.

- Reduction of corridor spans to $180 \mathrm{~m}$. This was based on numerical modelling results to ensure ERR were below industry requirements.

- The destress cut layout was changed to a herringbone configuration to reduce both $90^{\circ}$ turnouts and 4 -way intersections. The $17 \mathrm{~m}$ vertical spacing between destress cuts were maintained.

The method was trialled in early 2015. From mid-2015 to mid-2016, the mine used both LPS and the new HPS methods. By mid-2016, all new destress cuts were mined as per the new design. In 2017, a modification to the design to incorporate a trial of $8 \mathrm{~m}$ wide $\times 20 \mathrm{~m}$ long yield pillars was undertaken. This new design also had twin MADs access and allowed for workshops on each destress level.

\section{Ground support systems}

Ground support in destressed rockmass used the Garock Hybrid ${ }^{\mathrm{TM}}$, a dynamic friction bolt and $5.6 \mathrm{~mm}$ gauge weld-mesh in the development. The is support scheme was installed across the backs of the drive, down the sidewalls to $1.5 \mathrm{~m}$ from the floor on a $1.4 \mathrm{~m} \times 1.2 \mathrm{~m}$ spacing. Cable bolts were to be installed in intersections and at longhole stope brows. All ground support was mechanically installed. In 2018 shotcrete was added to the support scheme to reduce pillars unravelling below the mesh line. 


\section{Ground performance}

The HPS method showed instant improvement in rockmass conditions during the development of the destress cut. Less convergence was observed with $\sim 200 \mathrm{~mm}$ the maximum. Over the first 18 months of the HPS trial, it was observed that the $6 \mathrm{~m}$ wide $\times 10 \mathrm{~m}$ long pillars were yielding to the point of crushing. It was found that the highly fractured rockmass in the yield pillars was unravelling below the mesh line causing the further reduction in pillar size. Rockmass conditions further improved with the larger pillars which are currently in use today, (See Figure 11a and Figure 11b)

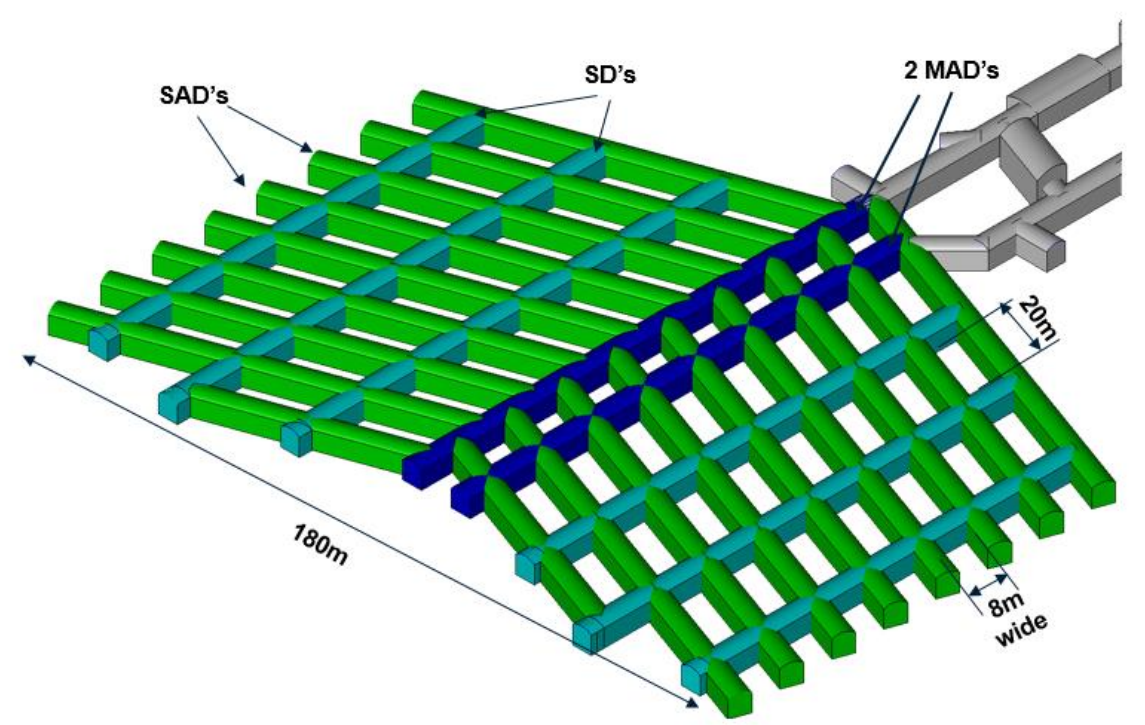

Figure 10. Oblique view of the latest mechanised high profile (HPS) destress mining method with larger yield pillars

\section{Production}

This method was utilised for 2 years from 2015 to 2016. The production rate built up from the 2014 low to1.24Mt extracted in 2015, increasing again in 2016 to 1.72Mt. The change to larger yield pillars in 2017 saw production remain consistent with $1.61 \mathrm{Mt}$ extracted. During these years, some $55 \%$ of total tonnes came from development.

\section{Seismicity}

Since the inception and ongoing use of the HPS method, monthly seismic energy released was between $5 \mathrm{MJ}$ and $60 \mathrm{MJ}$, with the average being <20 MJ/month. The reduction in the energy released, the number and magnitude of events whilst using the HPS method is attributed to the reduced levels of convergence. Larger events still cluster around stability pillars and on major structures whilst smaller events $\left(\mathrm{M}_{\mathrm{L}}-1.0\right.$ to 2.0$)$ are concentrated around the destress mining front. 

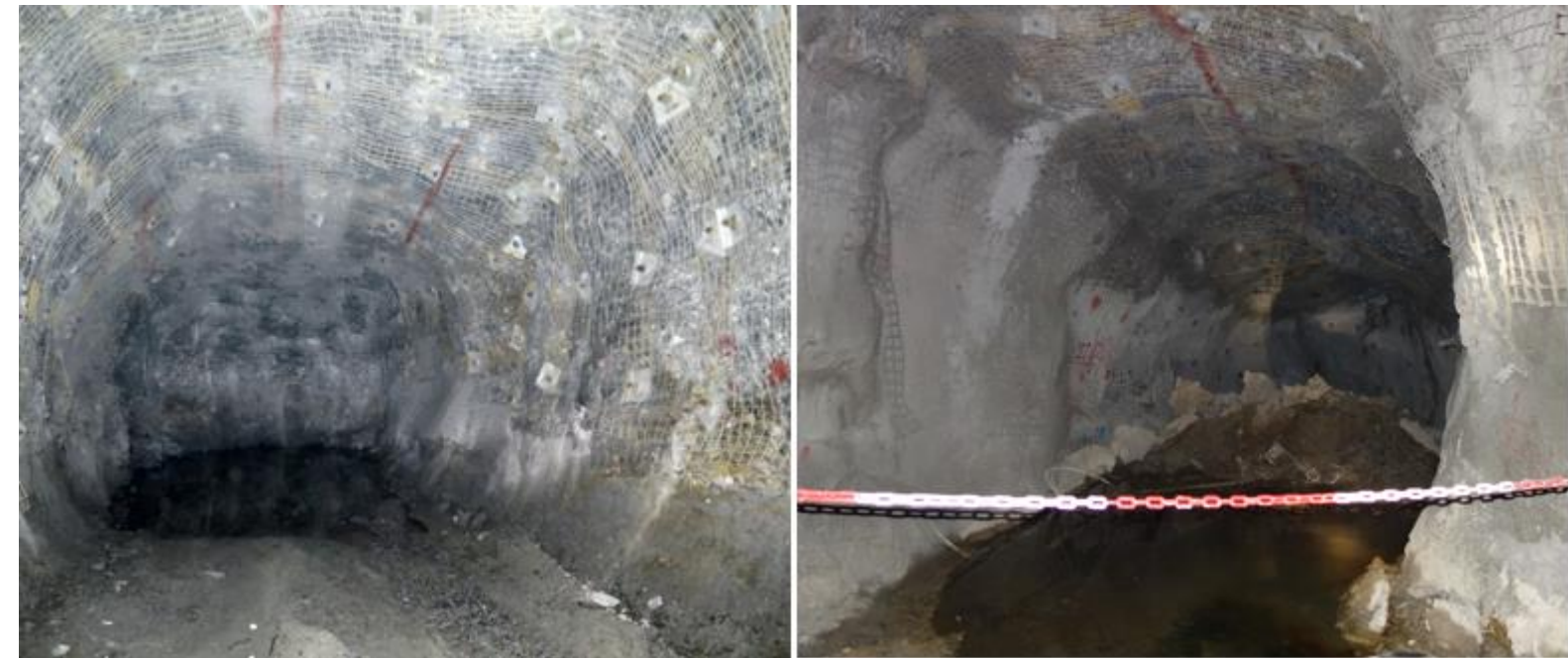

Figure 11a. HPS development with bolts and mesh
Figure 11b. HPS development with fibrecrete

\section{CONCLUSION}

Over the years, the South Deep mine has made considerable inroads into developing a fully mechanised mining method to laterally and vertically extract the extensive ore body. All methods have taken advantage of the destress philosophy which incorporates a tabular mining cut to be taken within the target package to destress the rockmass above and below the tabular cut.

Mining methods have changed over the years from low profile apparent dip destress method without pillars, followed by a horizontal low-profile method, initially without pillars, then using crush pillars as part of the sequence (LPS). Due to the inability to install mechanised ground support and poor rockmass conditions produced by the LPS methods, a high-profile method with mechanised support installation was adopted to the latest high-profile method with large yield pillars.

The latest HPS method creates a safer working environment for the workforce with industry best practice support standards, releases less seismic energy than the LPS methods whilst still allowing appropriate productivity rates.

The South Deep rock engineering team has used an observational method to continually assess ground conditions, pillar stability, and development convergence to allow ongoing optimisation and changes to each method culminating in the current HPS method with large yield pillars.

\section{ACKNOWLEDGEMENTS}

The authors would like to acknowledge the South Deep management team for their assistance in writing this paper.

\section{REFERENCES}

SRK. South Deep regional pillar optimization study (Stage II). Report 352262/2 to South Deep, dated February 2006. 
SRK. Rock engineering assessment of proposed horizontal destress cuts and massive mining at South Deep. Report 396956/1 to South Deep, dated February 2009.

James, J.V., MacDonald, A.J. and Raffield, M.P. (1998). The backfilling philosophy for massive mining at depth in the South Deep Section, Western Areas Gold Mine. Proceedings of the Sixth International Symposium on Mining with Backfill. Bloss, M.L. (editor) Australasian Institute of Mining and Metallurgy.

Jager, A.J. and Ryder, J.A. (1999). A handbook on rock engineering practice for tabular hard rock mines. The Safety in Mines Research Advisory Committee (SIMRAC). Braamfontein, RSA.

Joughin, W.C, Bester, W.M, and Du Plooy, M. (2011). Mining methods and backfill at South Deep Gold Mine. Minefill 2011, International Conference on Mining with Backfill, The Southern African Institute of Mining and Metallurgy, 2011.

Watson, B.P., Pretorius, W., Mpunzi, P., Du Plooy, M., Matthysen, K., and Kuijpers, J.S. (2014). Design and positive financial impact of crush pillars on mechanised deep-level mining at South Deep Gold Mine. Journal of the Southern African Institute of Mining and Metallurgy, volume 114, n 10, Johannesburg October 2014.

Ozbay, M.U., Jager, A.J. and Ryder, J.A. (1995). The design of pillar systems as practised in shallow hard-rock tabular mine sin South Africa, The Southern African Institute of Mining and Metallurgy, January/February 1995.

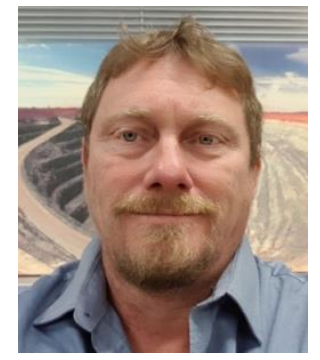

\section{Peter Andrews}

Vice President and Group Head of Geotechnical

Gold Fields

Peter has over 20 years of experience in the mining industry in both operating and consulting capacities. He has a broad range of experience with specific expertise in underground rock mechanics in the geotechnical engineering field. Over this period, he has obtained international industry experience, having worked on a number of large underground operations in Australia, New Guinea, South Africa, and South America. He specialises in underground stability analysis, extraction sequencing and ground support. 